doi:10.17659/01.2019.0044

Journal of Case Reports 2019;9(3):170-173

\title{
Small Cell Lung Cancer Presenting as a Benign Subcutaneous Mass on the Frontotemporal Region
}

\author{
Melihcan Sezgic ${ }^{1}$, Yasemin Aydinli ${ }^{2}$, Savas Serel ${ }^{2}$ \\ Department of Plastic, Reconstructive and Aesthetic Surgery, ${ }^{1}$ Bagcilar Research and Training Hospital, Istanbul, Turkey; ${ }^{2}$ Ankara \\ University Faculty of Medicine, Ankara, Turkey.
}

\begin{abstract}
Corresponding Author:
Dr. Melihcan Sezgic

Email:mlh_s@yahoo.com

This is an Open Access article distributed under the terms of the Creative Commons Attribution License (creativecommons.org/ licenses/by/3.0).
\end{abstract}

Received Accepted

Published

March 5, 2019

July 29, 2019

August 15, 2019

\begin{abstract}
Background: Lung cancer is the second most common cancer in United States and small cell lung cancer is responsible for $13 \%$ of all lung cancer cases globally. Soft tissue metastasis is rare in small cell lung cancer. Case Report: Here we describe a case of male patient admitted to hospital with a growing lesion on left frontotemporal region for one year time period. The patient was operated without any diagnostic modalities because of the lesion's typical findings like lipoma (regular borders, soft, mobile). Pathologic examination showed small cell lung cancer metastasis originated from lung. Conclusion: We discuss metastasis to face in lung cancer cases is rare and initial presentation as a mass on the face even more unusual. This case is a good example which shows patients may be admitted to plastic surgery department with atypical symptoms rather than typical symptoms of malignancies.
\end{abstract}

Keywords: Lipoma, Lung Neoplasms, Male, Sarcoma, Small Cell Lung Carcinoma.

\section{Introduction}

Lung cancer is the most mortal type of cancer, also is the second most commonly diagnosed cancer among men and women in the United States and in both sexes lifetime risk of being diagnosed with lung cancer is $6 \%[1,2]$. Small cell lung cancer (SCLC) is different within the range of lung cancers, because of its different clinical and histological characteristics and highly metastatic potential. Furthermore SCLC accounts of $13 \%$ of all new lung cancer cases globally [3]. Approximately $70 \%$ of SCLC cases presents with extensive disease [4]. Most common metastatic sites includes liver, brain, adrenal glands and bones.

Soft tissue (ST) metastasis is a sign of advanced disease and regarded as a poor prognostic indicator. However ST metastasis is uncommon in lung cancer with a prevalence of $2.3 \%$ [5]. Adenocarcinoma is the leading cause of soft tissue metastasis among all lung cancer types while SCLC is more rare [6,7]. In this present case report we discuss a patient with soft tissue mass on frontotemporal region and was diagnosed as metastasis of SCLC.

\section{Case Report}

Sixty-one-year old, smoker male patient was admitted to the hospital with a growing lesion on left frontotemporal region for one year time period. The lesion occurred 10 years ago after a traffic accident. He had no other health problem except chronic obstructive pulmonary disease (COPD) which was followed up by thoracic medicine. Upon physical examination, soft and mobile mass $(3 \times 3 \mathrm{~cm})$ with regular borders on frontotemporal region was discovered [Fig.1].

Because of typical physical findings, patient was operated under general anesthesia without any diagnostic modalities with the pre-diagnosis of 
lipoma. During surgery, because of mass's pale and whitish color other than lipoma, difficulty in dissection from surrounding tissues and showing lobulation on macroscopic examination, lipoma pre-diagnosis was excluded and specimen was sent to pathology as a primary or metastatic malignancy [Fig.2]. Pathology of specimen was reported as "high grade pleomorphic cell undifferentiated malignant tumor". After immunohistochemical evaluation, additional report was "metastasis of a malignant tumor which is showing neuroendocrine differentiation, supportive findings of lung origin SCLC metastasis". After performing thoracoabdomino-pelvic computerized tomography, hilar mass on left lung, mediastinal and left hilar lymphadenopathy was detected. Patient was directed to medical oncology department after this diagnosis for evaluation of metastatic disorder.

\section{Discussion}

Lung cancer is most abundently encountered among men while among women it ranks fourth globally and also it is the leading cause of mortality worldwide [8]. Nearly $50 \%$ of the cases are metastatic at the primary diagnostic stage and approximately $60 \%$ of patients have microscopic or clinically evident metastasis during the primary tumor treatment [9-11]. Major metastatic sites include liver (33-40\%), brain (15-43\%), bone (19-33\%), kidney (16-23\%) and abdominal lymph nodes (29\%) [10]. SCLC is responsible for approximately $15 \%$ of lung neoplasms and has the tendency to spread quickly, also has a high incidence of early systemic dissemination and most commonly occurs in the lung $[3,7]$. SCLC carries the greatest disposition for premature metastasis and it has a worse prognosis compared to the other histological types of lung cancer. Due to the aggresive nature of SCLC, the overall 5 year survival is about $5 \%$, for metastatic SCLC the average 5 year survival rate is $<1 \%$ [9].

Soft tissue metastasis are seldom, easily misdiagnosed in examination and also histologically

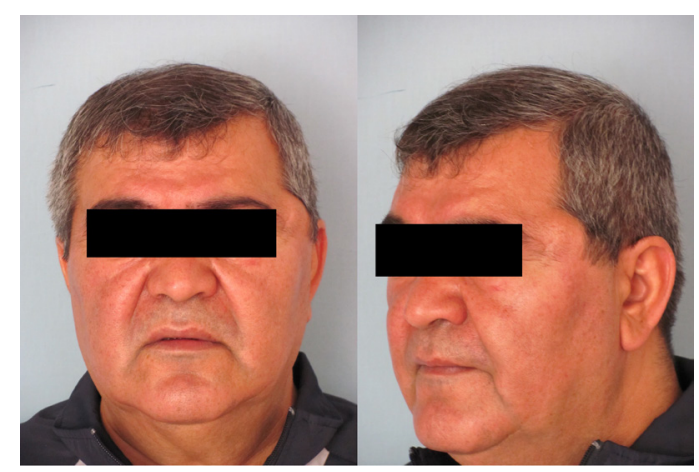

Fig.1: Preoperative photo of the patient, showing the mass on the left frontotemporal region.

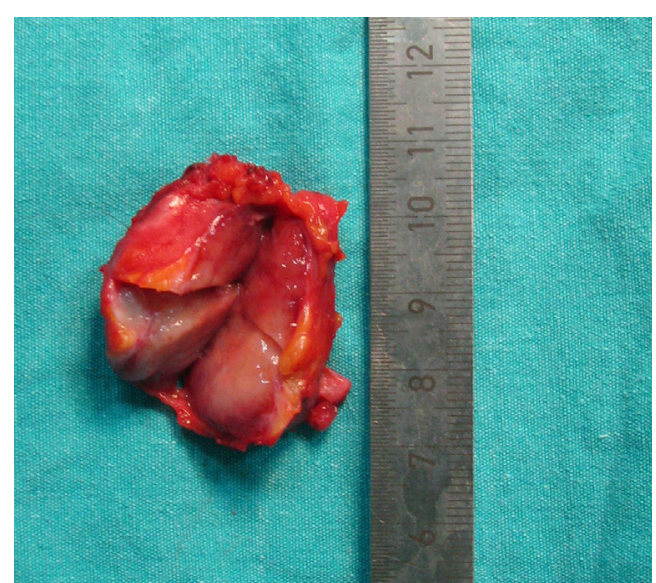

Fig.2: Intra-operative photo of the mass, lobulation and whitish color was noticed.

for primary soft tissue tumors. Identification of the mass is crucial, because the treatment and prognosis are different [6]. ST metastasis is a rare occuring incidence in lung cancer patients with a prevalence of $2.3 \%$ and the evidence from the past literature highlight that distant metastasis to the soft tissue is rarely encountered $[5,10]$. The detection of ST metastasis may result in alterations to the staging and prognosis of the cancer.

Patient's medical history revealed that the mass was formed after a traffic accident 10 years ago and started to change in size a year ago. In this case, the patient had no family history of cancer, he had respiratory distress due to COPD. According to the results of macroscopic evaluation during the diagnostic stage the mass was found to 
be soft, mobile and regulary bordered. Due to these characteristics of the mass, the consensus was that the mass was a benign structure similar to a lipoma therefore no further tests were performed for diagnosis. However previous case reports in the literature have highlighted the importance of fine needle aspiration for the diagnosis of masses with similar structural behaviours $[12,13]$. This discrepancy could be attributed, as a limitation for the present case report.

Metastasis to the face in lung cancer cases is very rare and an initial presentation in the face is even more unusual. Veerappan et al. [14] reported a squamous cell lung cancer presenting as a soft tissue mass on malar region. In contrast to our findings, the authors reported that upon physical examination the mass was firm, immobile and the visual field was affected by the mass effect. SCLC with isolated soft tissue metastasis of the face at initial diagnosis had not been reported before. Plaza et al. [6] reviewed 118 soft tissue metastasis cases and 14 of them the primary tumor origin were lung. Eight of them were adenocarcinoma, three of them were SCLC, two of them were squamous cell carcinoma and one was large cell carcinoma. In the majority of cases the mass was located on trunk, there was no metastasis located in the facial region.

There have been several investigations regarding atypical metastasis of cases with SCLC. Yildiz et al. [15] encountered a metastatic mass of SCLC inside the external auditory canal that had lead to admission of the patient with acute facial paralysis. Also Thottian et al. [16] come across 38 years old female patient which had a gingival metastasis of SCLC. Moreover Delgadillo et al. [17] diagnosed SCLC metastasis with excisional biopsy from the right $3^{\text {rd }}$ metatarsal bone of a 42 year old non-smoker patient. Sakellakis et al. [18] reported iris metastasis of SCLC on a patient receiving chemotherapy and radiotheraphy for SCLC. Furthermore tonsillar metastasis of SCLC was mentioned on previous literatures multiple times [19-21].

\section{Conclusion}

This case report presents a case report of metastatic mass diagnosed as SCLC on the face of the patient. Regardless of the benign characteristics of the mass the physician should evaluate diagnostic studies for suspicious masses. Sometimes a mass with a simple apperance may be an indication of a much complicated problem.

Contributors: MS: manuscript writing, patient management; YA: manuscript editing, patient management; SS: critical inputs into the manuscript. MS will act as a study guarantor. All authors approved the final version of this manuscript.

Funding: None; Competing interests: None stated.

\section{References}

1. Siegel RL, Miller KD, Jemal A. Cancer Statistics, 2017. CA: A Cancer Journal for Clinicians. 2017;67:7-30.

2. Howlader N, Noone AM, Krapcho M, Miller D, Bishop $\mathrm{K}$, Altekruse SF, et al.(eds). SEER Cancer Statistics Review, 1975-2013, National Cancer Institute. Bethesda, MD, http://seer.cancer.gov/csr/1975_2013/, based on November 2015 SEER data submission, posted to the SEER web site, April 2016.

3. van Meerbeeck JP, Fennell DA, De Ruysscher DK. Small-cell lung cancer. The Lancet. 2011;378:17411755 .

4. Jackman DM, Johnson BE. Small-cell lung cancer. The Lancet. 2005;366:1385-1396.

5. Sinha N, Niazi M, Diaz-Fuentes G, Duncalf R. An innocent appearing subcutaneous nodule diagnoses a small cell lung cancer in a never-smoker female. Case Reports in Oncological Medicine. vol. 2014, Article ID 268404.

6. Plaza JA, Perez-Montiel D, Mayerson J, Morrison C, Suster S. Metastases to soft tissue. Cancer. 2008;112:193203.

7. Ibrahim NBN, Briggs JC, Corbishley CM. Extrapulmonary oat cell carcinoma. Cancer. 1984;54:1645-1661.

8. Ferlay J, Parkin DM, Steliarova-Foucher E. Estimates of cancer incidence and mortality in Europe in 2008. European Journal of Cancer. 2010;46:765-781.

9. Horn L, Pao W, Johnson DH. Neoplasms of the lung. In: Longo DL, Kasper DL, Jameson JL, Fauci AS, Hauser SL, Loscalzo J, editors. Harrison's Principles of Internal Medicine, 18th ed., USA: McGraw-Hill; 2012. pp. 737-753.

10. Perisano C, Spinelli MS, Graci C, Scaramuzzo L, Marzetti E, Barone C, et al. Soft tissue metastases in 
lung cancer: a review of the literature. Eur Rev Med Pharmacol Sci. 2012;6:1908-1914.

11. Baldeo C, Ali R, Seeram V, House J. Lung Cancer presenting as a soft-tissue metastasis. Case Rep Oncol. 2015;8:185-188.

12. Pektas ZO, Gunhan O. Cytologically diagnosed metastatic small cell lung carcinoma in the mandibular soft tissue. Saudi Medical Journal. 2013;34(5):539-541.

13. Tomar LR, Agarwal MP, Aggarwal A, Narang S, Mishra K. Scalp swelling: An unusual presentation of small cell lung carcinoma. Indian Dermatol Online J. 2015;6:5557.

14. Veerappan G, Lettieri C, Cuneo B. Squamous cell lung cancer presenting as a malar mass. Neoplasia. 2003;5(5):467-468.

15. Yildiz O, Buyuktas D, Ekiz E, Selcukbiricik F, Papila I, Papila C. Facial nerve palsy: An unusual presenting feature of small cell lung cancer. Case Rep Oncol. 2011;4:35-38.

16. Thottian AGF, Pathy S, Gandhi AK, Malik PS. Coughing up - Small cell carcinoma lung with gingival metastasis.
J Egypt Natl Canc Inst. 2016 Oct 18. pii: S11100362(16)30058-9.

17. Delgadillo LA, Nichols DE. Oat cell carcinoma metastasis of the foot. J Foot Ankle Surg. 1998;37:5562.

18. Sakellakis M, Peroukides S, Iconomou G, Kalofonos H. Iris metastasis in a patient with small cell lung cancer: A case report. Iranian Red Crescent Medical Journal. 2016;18(4):e21522.

19. Kim EJ, Kim SR, Jin Gang S, Park SY, Han YM, Lee YC. Tonsillar metastasis of small cell lung cancer in a patient with idiopathic pulmonary fibrosis: a case report. Medicine (Baltimore). 2015;94:e565.

20. Chen XH, Bao YY, Zhou SH, Wang QY, Zhao K. Palatine tonsillar metastasis of small-cell neuroendocrine carcinoma from the lung detected by FDG-PET/CT after tonsillectomy: A Case Report. Iran J Radiol. 2013;10(3):148-151.

21. Unsal M, Kutlar G, Sullu Y, Yurtlu S. Tonsillar metastasis of small cell lung carcinoma. The Clinical Respiratory Journal. 2016;10:681-683. 